\title{
O comportamento estratégico e o fator de munificência em empresas da cidade de Icó: um estudo baseado na tipologia de Miles e Snow
}

\section{The strategic behavior and munificence factor in city business Icó: a study based on the typology of Miles and Snow}

Ismar Gurgel Coqueiro ${ }^{1}$ Alyne Leite de Oliveira ${ }^{2}$

\section{Resumo}

O presente artigo tem como objetivo identificar o perfil do comportamento estratégico em empresas da cidade de Icó juntamente com o ambiente percebido pelos empresários, através da tipologia de Miles e Snow (1978), que diferencia o comportamento das empresas de acordo com sua estratégia em: prospectoras, analíticas, reativas e defensivas. O método utilizado na pesquisa foi uma survey do tipo descritiva, com abordagem quantitativa. Para a amostra, foram utilizadas empresas cadastradas na Câmara de Dirigentes Lojistas (CDL). O questionário utilizado para captação do comportamento estratégico foi o de Conaltetal (1990), e para quantificar a munificência ambiental das empresas foi utilizado o questionário de Castrogiovani (1991). As empresas icoenses são, em sua maioria, do tipo prospectoras (36\%) e apresentam alta munificência para o ambiente em que estão inseridas. Quanto à relação da munificência com o comportamento estratégico, não houve significância estatística $(\alpha<0,05)$. Diferentemente do que propõe a população, o campo empresarial da cidade é favorável ao desenvolvimento. As empresas que atuam na localidade estão se inserindo em um novo modelo empresarial e necessitam de credibilidade e confiança da população para dinamizar e adequar-se ainda mais ao cenário econômico global.

Palavras-chave: Miles e Snow. Munificência. Estratégia. Comportamento.

Administrador, MBA em Negócios e Professor EMI no Centro de Ensino Tecnológico do Ceará CENTEC. E-mail: ismarcoqueiro@hotmail.com(88) 96408777

2 Especialista em Logística empresarial pela Faculdade de Juazeiro do Norte- FJN. E-mail: alyneleite@hotmail.com (88) 99533321 


\section{Abstract}

This article aims to identify the profile of the strategic behavior of companies in the city of Icó with the environment perceived by entrepreneurs through the typology of Miles and Snow (1978) that differentiate the behavior of firms according to their strategy: Prospectors, Analytical, Reactive and defensive. The method used in the study was a survey with a descriptive and quantitative approach.For the sample used was registered companies $C D L$, the questionnaire used to capture the strategic behavior was to Conalt et al (1990), and to quantify the munificence of corporate environmental questionnaire was used to Castrogiovani (1991). The companies' city are mostly the type prospectors (36\%) and had a high bounty for the environment in which they operate, as the relationship with the munificence of strategic behavior, no statistically significant $(\alpha<0,05)$. Unlike proposing the population, the cityss business field is conducive to development and the companies operating in the locality are entering into a new business model and need the credibility and trust of the population to streamline and adapt itself to the further economic scenery global.

Keywords: Miles and Snow. Munificence. Strategic. Behavior.

\section{Introdução}

Os desafios que cercam as empresas atualmente são provenientes do ambiente no qual elas estão inseridas. Desse modo, estudar o ambiente das empresas é sempre uma contribuição para o mercado e para a sociedade, haja vista que conhecer o ambiente é conhecer de fato o perfil das empresas.

As pequenas empresas possuem menos informações e estudos que expliquem os acontecimentos nessa parte empresarial, assim, são necessários estudos que mostrem como as elas se comportam no cenário empresarial almejando maximizar a sua participação ou mesmo dar um passo inicial para a formulação de uma estratégia adaptada ao mercado em que elas vivem. Que tipo de comportamento as empresas icoenses possuem frente ao ambiente disponível?

Nessa linha de pensamento pretende-se verificar o comportamento estratégico das pequenas empresas na cidade de Icó, juntamente com a munificência de recursos, a partir da percepção dos gestores. 
A realização do estudo na cidade de Icó se justifica pelo fato de a localidade possuir o reconhecimento de cidade histórica, com empresas tradicionais que possuem líderes hierárquicos.

Na opinião pública, o local não cresce de forma abundante por causa do comportamento não empreendedor das empresas. Desse modo, pretendeu-se mostrar se as empresas da cidade se comportam de maneira defensiva, analítica, prospectora ou reativa, de acordo com a tipologia de Miles e Snow (1978), e ainda quanto à presença de recursos nesse cenário.

O conhecimento do ambiente externo, bem como o posicionamento do comportamento no mercado, propicia à empresa uma maior visão de suas oportunidades e ameaças, contribuindo com a revitalização de casos críticos e servindo de modelo para outras áreas a serem estudadas. A tipologia de Miles e Snow (1978) foi escolhida para esta pesquisa por já ter uma boa aceitação e apresentar cerca de $60 \%$ de aceitação nas pesquisas feitas com essa metodologia, além de uma estrutura fácil e ao mesmo tempo completa, capaz de identificar o perfil da empresa em quatro dimensões que facilitam o entendimento do mercado local.

O ambiente que cerca as empresas é o mesmo, desse modo, daria a pensar que todas possuem a mesma oportunidade de mercado e as mesmas ferramentas para conquistar o sucesso, porém, isso não acontece por alguns fatores, e um primordial é a estratégia, que muda de empresa para empresa (HALL, 1984).

É importante qualquer empresa conhecer sua estratégia e fazer constantes mudanças, seja de modo adaptativo ou mesmo de caráter radical, pois isso é necessário devido às constantes mudanças do ambiente externo, que não trata todas as empresas igualmente. $O$ objetivo deste trabalho é identificar o perfil comportamental estratégico de pequenas empresas na cidade de Icó, fazendo uma inter-relação com a percepção de munificência ambiental dos seus proprietários.

A pesquisa conta com os seguintes objetivos específicos: estudar a presença de incentivos externos em prol das empresas locais; entender os principais conceitos de comportamento estratégico a partir 
da teoria existente; e associar o comportamento estratégico como fator de munificência encontrado.

E para revisar a importância dessa tipologia, outros estudos foram feitos em aplicação a esse modelo e que obtiveram êxito nos resultados, dentre os quais se destacam: GARDELIN, 2010; GIMENEZ, 1999; GULINI, 2005; TEIXEIRA, 2007; TONDOLO; TONDOLO, 2006.

\section{0 conceito de estratégia}

Antigamente, o termo "estratégia" significava as alternativas e aparatos que os generais possuíam disponíveis para os combates militares, visando ser o melhor entre os seus inimigos de guerra (MOTTA, 2002). Após sucessivas mudanças, tanto na sociedade quanto na tecnologia, foram surgindo múltiplos significados de estratégia. As pesquisas na área estabeleceram relações do conceito de estratégia com os ambientes, o que levou a colaborar com a estrutura empresarial (CHANDLER, 1962; LAWRENCE; LORSCH, 1973)

Durante toda essa evolução no seu conceito, através dos diversos aspectos e variáveis de influência em diversos campos do conhecimento, a estratégia tem sido reconhecida como algo relevante na gestão das empresas e constituído foco de múltiplas pesquisas, pela sua importância indiscutível para o campo da administração. A respeito do impacto e resultados visíveis que a gestão estratégica possui atualmente, os pensamentos sobre estratégia já existiam antes de Cristo, e os embasamentos que fundamentam essa área da ciência gerencial vem evoluindo ao longo do tempo e enriquecendo com diversas novas perspectivas (MINTZBERG; AHLSTRAND; LAMPEL, 2000).

Aintenção da estratégia empresarial é identificar quais os caminhos existentes, tendo o controle de qual a empresa está seguindo e qual a melhor alternativa para se chegar ao objetivo ou resultado esperado (OLIVEIRA, 2009).

As pequenas empresas, na sua maioria, não possuem estratégias definidas formalmente, o que não quer dizer que não tenham um 
planejamento informal para dar rumo aos projetos e objetivos de curto e longo prazo.

Na presente pesquisa, denomina-se a estratégia como subdividida por dois aspectos: um externo e outro interno. O externo abrange a estratégia com as empresas, sendo uma resposta aos desafios do mercado em geral. Em contrapartida, o interno trata dos processos e da estrutura que a empresa possui para adequar-se às turbulências estratégicas do mercado (TEIXEIRA, 2007).

3 Modelo estratégico de Miles e Snow

O modelo de Miles e Snow é eficiente no diagnóstico do comportamento das estratégias empresariais das mais diversas empresas independentes, sendo capaz de destacar o perfil delas num universo dividido em quatro dimensões, de acordo com o seu comportamento no mercado: prospectora, analítica, reativa e defensiva (FAGUNDES; GIMENEZ, 2009).

A partir dos três problemas estruturados por Miles e Snow (1978), é possível identificar o comportamento estratégico da empresa, pois de acordo com a tomada de decisão em prol desses problemas se definem traços comportamentais, os quais Miles e Snow predefiniram em quatro tipos estratégicos. Os problemas podem ser vistos na Figura 1:

Figura 1: O ciclo adaptativo

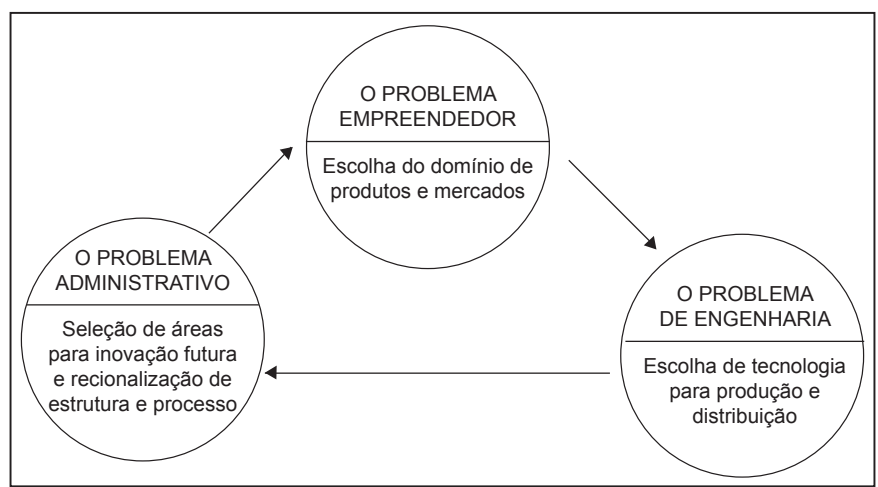

Fonte: Miles e Snow (1978, p. 24). 
Esses três problemas representados pelo modelo de Miles e Snow estão relativamente agrupados em si e não possuem uma ordem lógica de iniciação, embora normalmente inicie-se com o problema empreendedor. No entanto, também se pode começar a estudar pelos outros dois, como apresentado por Froés (2009), em que as decisões tomadas no período inicial tende a se solidificar como parte da estrutura posterior.

O líder de uma empresa deve sempre ficar atento, com o propósito de equilibrar os resultados nos três níveis da empresa (administrativo, engenharia e empreendedor), formando assim um ciclo positivo, sem desperdício de tempo, sem retrabalho, com o objetivo de alcançar resultados positivos e diferenciais competitivos em relação aos concorrentes (CHICHOSKI; CERETTA; ROCHA, 2013).

De acordo com os conceitos de Miles e Snow (1978), esses três tipos estratégicos são considerados alinhados porque, quando definido um objetivo considerando produto-mercado, a empresa amplia suas respostas adaptando em tecnologia, manufatura, sistemas, processos e controles, para que a escolha estratégia possa ser corretamente implantada, maximizando sua eficácia e competitividade. De outro modo, a empresa teria respostas tardias às oportunidades e certamente seria pouco eficiente. O alinhamento é, dessa maneira, uma fonte importante de diferencial competitivo.

A eficiência dessa tipologia é mostrada no diagnóstico do comportamento estratégico nos diversos estudos já feitos no mundo, ainda pela sua adaptabilidade ao novo contexto empresarial do século XXI, diferentemente de outros estudos, como o de Porter (1980), que, de acordo com Mintzberg (1988), não se aplica eficientemente nos anos seguintes, devido às constantes mudanças do mercado (GIMENEZ, 1999). 
Quadro 1: Tipologia de Miles e Snow

\begin{tabular}{|l|l|}
\hline Categoria Estratégica & \multicolumn{1}{|c|}{ Descrição } \\
\hline Estratégia defensiva & $\begin{array}{l}\text { A empresa procura localizar e manter uma linha de produtos/serviços } \\
\text { relativamente estável. O seu foco se concentra em uma gama de } \\
\text { produtos/serviços mais limitada do que a de seus concorrentes e tenta } \\
\text { proteger o seu domínio por meio da oferta de produtos com melhor } \\
\text { qualidade, serviços superiores elou menores preços. Não procura estar } \\
\text { entre os líderes da indústria, restringindo-se àquilo que sabe fazer tăo } \\
\text { bem ou melhor que qualquer um. }\end{array}$ \\
\hline Estratégia prospectiva & $\begin{array}{l}\text { A empresa está continuamente ampliando a sua linha de } \\
\text { produtos/serviços. Enfatiza a importância de oferecer novos } \\
\text { produtos/serviços em uma área de mercado relativamente mais ampla. } \\
\text { Valoriza ser uma das primeiras a oferecer novos produtos, mesmo que } \\
\text { todos os esforços não se mostrem altamente lucrativos. }\end{array}$ \\
\hline Estratégia analítica & $\begin{array}{l}\text { A empresa tenta manter uma linha limitada de produtos/serviços } \\
\text { relativamente estável e, ao mesmo tempo, adicionar um ou mais novos } \\
\text { produtos/serviços que foram bem sucedidos em outras empresas do } \\
\text { setor. Em muitos aspectos é uma posiçắo intermediária entre as } \\
\text { estratégias defensiva e prospectiva. }\end{array}$ \\
\hline Estratégia reativa & $\begin{array}{l}\text { A empresa exibe comportamento mais inconsistente do que os outros } \\
\text { tipos. É uma espécie de năo-estratégia. Năo arrisca em novos } \\
\text { produtos/serviços, a năo ser quando ameaçada por competidores. A } \\
\text { abordagem tipica é "esperar para ver" e responder somente quando } \\
\text { forçada por pressóes competitivas, para evitar a perda de clientes } \\
\text { importantes e/ou manter a lucratividade. }\end{array}$ \\
\hline
\end{tabular}

Fonte: Miles e Snow (1978 apud COCHIA E MACHADO-DE-ASSIS, 2004, p. 18).

O Quadro 1 mostra a conceituação dos quatro modelos de comportamento de Miles e Snow (1978). Não são dados pontos negativos a nenhum deles, pois nenhum comportamento no mundo empresarial é dado como errado. Porém, a empresa pode estar se comportando de maneira inadequada para a ocasião e o ambiente que esteja vivendo.

Os estudos de Miles e Snow (1978) foram tão significativos para o estudo das estratégias no mundo que se tornaram base para diversos outros pensamentos e ideias. Destaca-se Gurkov (2007), que combinou a tipologia de Miles e Snow (1978) com a abordagem de Bowman e Faulkner (1997), criando variáveis que representam aspectos da competitividade e inovação das empresas, chamando-as de: 1) outsider (baixa qualidade, preço, inovação, poucas competências e alto custo); 
2) coast defender (baixa qualidade, preço, custo, poucas competências e moderada inovação); 3) quality defender (alta qualidade, preço e competências e custos e inovação moderada); 4) analyzer (alta qualidade, preço, competências e custos e moderada inovação); 5) prospector (alta qualidade, competências e inovação e preço e custo baixos); e 6) monopolist (qualidade e preço relativos, custo e competências variáveis e inovação reprimida).

A postura prospectora é resultado das empresas que constantemente buscam oportunidades mercadológicas e provam as articulações emergentes do ambiente. Sempre criando mudanças no cenário econômico e riscos aos quais os concorrentes devem adaptarse e mostrar alternativas como feedback, têm também uma boa estruturação de recursos humanos, porém o inconformismo em inovar nem sempre se torna um caso de sucesso (RIBEIRO et al., 2001).

As empresas que seguem a estratégia analítica tentam manter uma linha limitada de produtos e serviços. O processo de inserção de novos produtos e serviços é inspirado nas apostas exitosas de outras empresas do ramo, assim, conclui-se que é uma posição intermediaria entre a estratégia defensiva e a prospectora (MAXIMIANO, 2007).

Já na postura reativa, os gestores imediatamente percebem as mudanças ambientais e as suas incertezas, mas não possuem capacidade de dar respostas ativas a elas. Essa incapacidade é proveniente da inexistência de um vinculo estratégia-estrutura presente nessas empresas, que dificilmente realizam modificações de qualquer tipo, a menos que se sintam pressionadas pelo ambiente externo (MILES; SNOW, 1978 apud BRESSAN, 2011).

Por fim, o comportamento defensivo diz respeito a uma empresa que possui curto domínio do produto-mercado. Os gestores são altamente especializados em uma limitada área de operação da empresa, não havendo preocupação em procurar novas oportunidades fora das suas áreas de domínio. Como consequência, essas empresas raramente realizam transformações em sua estrutura, tecnologia ou 
operações organizacionais, dando maior atenção e eficiência às suas especialidades (BRESSAN, 2011).

Quadro 2: Comportamento do ciclo adaptativo e tipos estratégicos.

\begin{tabular}{|c|c|c|c|c|c|}
\hline \multirow{2}{*}{$\begin{array}{l}\text { Comportamento } \\
\text { do Ciclo } \\
\text { Adaptativo }\end{array}$} & \multirow{2}{*}{ Dimensöes } & \multicolumn{4}{|c|}{ Tipos Estratégicos } \\
\hline & & Defensiva & Prospectora & Analitica & Reativa \\
\hline \multirow{4}{*}{$\begin{array}{c}\text { Problema } \\
\text { Empreendedor e } \\
\text { Solupbos }\end{array}$} & $\begin{array}{l}\text { Dominio de } \\
\text { produtos e } \\
\text { mercados }\end{array}$ & $\begin{array}{c}\text { Estreito e } \\
\text { cuidadosamente } \\
\text { focado }\end{array}$ & $\begin{array}{l}\text { Amplo e em } \\
\text { expansão } \\
\text { continus }\end{array}$ & $\begin{array}{c}\text { Segmentado e } \\
\text { cuidadosamente } \\
\text { ajustado }\end{array}$ & $\begin{array}{l}\text { Irregular e } \\
\text { transitório }\end{array}$ \\
\hline & $\begin{array}{l}\text { Postura de } \\
\text { sucesso }\end{array}$ & $\begin{array}{l}\text { Proeminente em } \\
\text { seu mercado }\end{array}$ & $\begin{array}{l}\text { Ativa iniciaç5̄o } \\
\text { de mudança }\end{array}$ & $\begin{array}{l}\text { Seguidores } \\
\text { cuidadosos de } \\
\text { mudança }\end{array}$ & $\begin{array}{l}\text { Investidas } \\
\text { oportunistas e } \\
\text { postura de } \\
\text { adaptacio }\end{array}$ \\
\hline & $\begin{array}{l}\text { Moniforamento } \\
\text { ambiental }\end{array}$ & $\begin{array}{l}\text { Baseado no } \\
\text { dominio e } \\
\text { euidadosoltorte } \\
\text { monitoramento } \\
\text { organizacional }\end{array}$ & $\begin{array}{c}\text { Onentado para o } \\
\text { mercado e } \\
\text { ambiente / busca } \\
\text { agressiva }\end{array}$ & $\begin{array}{c}\text { Orientado para a } \\
\text { concorrència e } \\
\text { completo }\end{array}$ & $\begin{array}{l}\text { Esporbdico e } \\
\text { dominado por } \\
\text { tópicos } \\
\text { especificos }\end{array}$ \\
\hline & Crescimento & $\begin{array}{l}\text { Penetraçlo } \\
\text { cuidadosa e } \\
\text { avanços de } \\
\text { produtividade }\end{array}$ & $\begin{array}{l}\text { Desenvolvimento } \\
\text { de produtes e } \\
\text { mercados e } \\
\text { diversificaç̄o }\end{array}$ & $\begin{array}{c}\text { Penetraç5o } \\
\text { assertiva e } \\
\text { cuidadoso } \\
\text { desenvolvimento } \\
\text { de produtos e } \\
\text { meroados }\end{array}$ & $\begin{array}{l}\text { Mudanças } \\
\text { apressadas }\end{array}$ \\
\hline \multirow{3}{*}{$\begin{array}{c}\text { Problema de } \\
\text { Engenharia e } \\
\text { Solupbos }\end{array}$} & $\begin{array}{l}\text { Objetivo } \\
\text { tecnolbogico }\end{array}$ & $\begin{array}{l}\text { Efieièneia de } \\
\text { custos }\end{array}$ & $\begin{array}{l}\text { Flexibilidade e } \\
\text { inovaç̧๐ }\end{array}$ & $\begin{array}{l}\text { Sinergia } \\
\text { secnológica }\end{array}$ & 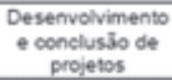 \\
\hline & $\begin{array}{l}\text { Amplitude } \\
\text { tecnológiea }\end{array}$ & $\begin{array}{c}\text { Tecnologia } \\
\text { única, focal } \\
\text { lexpetice básico }\end{array}$ & $\begin{array}{l}\text { Tecnologias } \\
\text { múltiplas I } \\
\text { avançadas na } \\
\text { frontteira }\end{array}$ & $\begin{array}{c}\text { Tecnologias } \\
\text { inter" } \\
\text { relaciopadas na } \\
\text { fronteira }\end{array}$ & $\begin{array}{l}\text { Aplicapóes } \\
\text { teconologicas } \\
\text { mutáveis I } \\
\text { fluidez }\end{array}$ \\
\hline & $\begin{array}{l}\text { Anteparos } \\
\text { tecnológioos } \\
\text { (buffera) }\end{array}$ & $\begin{array}{l}\text { Programas de } \\
\text { manutençĩo e } \\
\text { padronizaçäo }\end{array}$ & $\begin{array}{l}\text { Habilidades de } \\
\text { pessoal técnioo / } \\
\text { diversidade }\end{array}$ & $\begin{array}{c}\text { Incrementalismo } \\
\text { e sinergia }\end{array}$ & $\begin{array}{l}\text { Habilidade de } \\
\text { experimentar e } \\
\text { improvisar } \\
\text { solupojes }\end{array}$ \\
\hline \multirow{4}{*}{$\begin{array}{c}\text { Problemas } \\
\text { Administrativos e } \\
\text { Soluços }\end{array}$} & $\begin{array}{l}\text { Coalizio } \\
\text { dominante }\end{array}$ & $\begin{array}{l}\text { Finanças e } \\
\text { produç̧̇o }\end{array}$ & Marketing e PsD & $\begin{array}{c}\text { Pessoal e } \\
\text { planejamento }\end{array}$ & $\begin{array}{l}\text { Solucionadores } \\
\text { de problemas }\end{array}$ \\
\hline & Planejamento & $\begin{array}{l}\text { De dentro para } \\
\text { fora / dominado } \\
\text { por controle }\end{array}$ & $\begin{array}{c}\text { Busca de } \\
\text { problemas e } \\
\text { oportunidades I } \\
\text { perspectivas de } \\
\text { programas ou } \\
\text { campanhas }\end{array}$ & $\begin{array}{l}\text { Abrangentes } \\
\text { com mudanças } \\
\text { incrementais }\end{array}$ & $\begin{array}{l}\text { Orientado por } \\
\text { erises e } \\
\text { desarticulado }\end{array}$ \\
\hline & Estrutura & $\begin{array}{c}\text { Funcional / } \\
\text { Autoridade de } \\
\text { linha }\end{array}$ & $\begin{array}{c}\text { Por produto elou } \\
\text { mereados }\end{array}$ & $\begin{array}{c}\text { Dominada por } \\
\text { assessores / } \\
\text { orientada por } \\
\text { matrz } \\
\end{array}$ & $\begin{array}{l}\text { Autoridade } \\
\text { formal rigida / } \\
\text { desempenho } \\
\text { operacional solto }\end{array}$ \\
\hline & Controle & $\begin{array}{l}\text { Centralizado, } \\
\text { formal e } \\
\text { ancorado em } \\
\text { aspectos } \\
\text { financeiros }\end{array}$ & $\begin{array}{c}\text { Desemperiho no } \\
\text { mereado I } \\
\text { volume de } \\
\text { vendas }\end{array}$ & $\begin{array}{l}\text { Métodos } \\
\text { múltiplos I } \\
\text { cáleulos de } \\
\text { riscos } \\
\text { cuidadosos / } \\
\text { contribuiçajo de } \\
\text { vendas }\end{array}$ & $\begin{array}{l}\text { Evitar } \\
\text { problemas/ } \\
\text { resolver } \\
\text { problemas } \\
\text { remanescentes }\end{array}$ \\
\hline
\end{tabular}

Fonte: Miles e Snow (1978 apud GIMENEZ et al., 1999, p. 61). 
No Quadro 2, é possível caracterizar o comportamento da empresa, e foi a partir dele que Conant et al. (1991) idealizaram o questionário de 11 questões, levando em consideração cada dimensão e o problema proposto por Miles e Snow (1978).

\section{0 comportamento estratégico das pequenas empresas}

Os estudos sobre estratégias em pequenas empresas são muito mais recentes do que os realizados em organizações de grande porte, nos quais as correntes teóricas sobre estratégias competitivas tratavam de desenvolvimento e verificação de teorias cujo objetivo era maximizar o lucro (BANDEIRA-DE-MELLO; CUNHA, 2004).

O direcionamento do modelo de Miles e Snow (1978) para as pequenas empresas fez parte da identidade dessa tipologia desde sua criação. Com o mundo dando cada vez mais importância às pequenas empresas, e devido à deficiência de estudos nesse campo, despertou-se a atenção dos pesquisadores, que buscaram novas teorias e modelos que relatem a forma de comportamento de acordo com suas estratégias empresariais.

Torna-se um tanto quanto delicada a análise em pequenas empresas devido ao fator cultural da tendenciosidade. Pesquisadores do mundo todo acreditam que pesquisas feitas em pequenas empresas tendem a ser transformadas nos instrumentos de coleta de dados. Em relação a essa questão, propõe-se o posicionamento de Bressan (2011), segundo o qual toda organização vê aquilo que ela quer ver no seu ambiente externo e pode ser relevante em responder dessa forma, pois são as escolhas estratégicas que modificam as estruturas e os processos da organização.

O reconhecimento do ambiente empresarial é intrínseco à percepção do gestor: "o comportamento estratégico da organização está inteiramente ligado ao perfil do gestor, ele é o agente que impulsiona e principalmente direciona todas as ações para a busca da estratégia pretendida" (ARCHER et al., 2011, p. 6). 
As pequenas empresas, em sua maioria, não aparentam possuir estratégias explícitas, mas certamente têm um comportamento estratégico, que é fruto das principais atitudes tomadas pela empresa perante o mercado e também do modo como definem seus ideais ou segmentos específicos no cenário econômico (OLIVEIRA, 2009).

No Brasil, as pequenas empresas que são influenciadas pelo clima de incerteza vivem sérias dificuldades em definir uma estratégia, pois o planejamento das empresas nascentes é precário. Esse fator é mais agravante ainda nas empresas de pequeno porte, em que os proprietários dispõem de poucos conhecimentos do conjunto de planos que objetivam alcançar para consolidação dos objetivos gerais de curto, médio e longo prazo (GRANDE; GEUS; GEUS 2007).

Os fatores de dificuldades e a incipiência de estudos em empresas de pequeno porte inspiram autores, e o mesmo ocorreu para esta pesquisa, ao analisar o comportamento estratégico em pequenas empresas, colocando o ambiente externo como fator de relevância para o comportamento estratégico ambiental dessas empresas.

\section{0 fator de munificência nas organizações}

O estudo pioneiro de Penrose (1959) sobre a teoria baseada em recursos foi o marco inicial sobre o assunto. Para a autora, o que limita o crescimento da empresa não é exatamente o mercado, mas os recursos que possui e a maneira como são utilizados pela empresa. É a partir da distinção entre os recursos e a forma como são aproveitados que está a origem da singularidade das empresas.

Outros autores já fizeram essa inter-relação do comportamento estratégico com a percepção de munificência em um ambiente empresarial, em destaque o de Gardelin et al. (2010).

O ambiente pode ser considerado como "tudo o que está fora da organização - sua tecnologia; a natureza de seus clientes; sua posição geográfica; o clima econômico e até meteorológico em que deve operar" (MINTZBERG, 2008, p. 155). 
Estudar o comportamento estratégico paralelo à munificência de recursos é de grande relevância, pois um interage com o outro a ponto de ambos se influenciarem tanto para um campo positivo como negativo. A munificência de recursos é um indicador de como se encontra um determinado ambiente empresarial a respeito de vários fatores, como: presença de investimentos governamentais, clientes, fornecedores etc.

Um ambiente munificente nem sempre é sinônimo de sucesso para as empresas que vivem no cenário munificente, já que quanto mais munificente o ambiente, mais volátil ele passa a ser, pois a presença de recursos desperta o interesse de novos entrantes.

A abordagem de Miles e Snow, como referenciado por Gimenez et al. (1999), especifica os relacionamentos entre estratégia, estrutura e processo, os quais permitem que as organizações identifiquem uma interação com o ambiente no qual estão inseridos.

Seguindo a proposta de Escobar (2012), constata-se que a munificência modera a relação positiva que há entre a dimensão das empresas com comportamento prospector e o desempenho comparado aos demais comportamentos. Quanto maior o grau de munificência, mais empresas prospectoras devem emergir.

A produtividade das empresas pode mudar conforme as estratégias adotadas em determinados períodos pelas organizações. As estratégias são aplicadas em função do ambiente em que as organizações convivem. Assim, o conjunto de incógnitas formado por ambiente, estratégia e desempenho fica intensamente caracterizado pelo paradigma SPC (Structure-Condute-Performance). Essa parte da pesquisa pretende fazer uma conexão entre ambiente e estratégias, a fim de contextualizar as próximas secções que mostrarão as hipóteses e métodos utilizados neste estudo (GARDELIN, 2010).

Aalta presença ou a escassez de recursos disponíveis em um dado ambiente estão diretamente relacionadas à gestão de folga de recursos de uma empresa. Essa geração de folga de recursos é importante em empresas empreendedoras, já que permite à empresa organizar uma 
quantidade maior de recursos para a inovação e o desenvolvimento de novas táticas estratégicas (CARVALHO, 2011).

Levando em consideração que as mudanças no ambiente empresarial são dinâmicas, elas precisam ser continuamente controladas. Diversos autores tratam a atividade de análise do ambiente como a principal etapa do processo estratégico, portanto, determinar a presença de recursos disponíveis em um ambiente é propiciar informações valiosas para os empreendedores que venham a empreender na localidade estudada (ESCOBAR; LIZOTE; VERDINELLI, 2012).

Nos períodos clássicos, as teorias administrativas determinavam a organização como um sistema fechado, isto é, que não sofre nem exerce qualquer influência no seu ambiente externo. Desse modo, essas influências só passaram a ser reconhecidas e estudadas nesse âmbito quando foram idealizadas as organizações como sistemas abertos: "As organizações, como organismos, estão abertas ao seu ambiente e devem atingir uma relação apropriada com esse ambiente, caso queiram sobreviver" (MORGAN, 1996, p. 36).

O impacto da munificência ambiental sobre os procedimentos e o desempenho no setor organizacional têm recebido grande atenção na literatura (BARRALES-MOLINA et al., 2010; WIKLUND; SHEPHERD, 2005).

\section{Caracterização da economia pesquisada}

A palavra "Icó" é de origem indígena e significa "água ou rio da roça". Nome de uma tribo Tapuia da Nação Cariri-Icós, radicada nas margens do Rio Salgado (CE) e do Rio do Peixe (PB). Também uma nomeação de uma árvore da família Caparidáceas, conhecida como icozeiro. Antes de ser assim chamada, a cidade teve muitos outros nomes: Ribeira dos Icós, Arraial Velho, Arraial Novo, Arraial de Nossa Senhora do Ó, Sítio de Nossa Senhora do Ó dos Icós, Povoação do Salgado, Icó dos Fonsecas, Icó dos Montes e, finalmente, Icó (IBGE, 2011). 
A cidade de Icó, localizada no estado do Ceará, foi criada no ano de 1735. Está situada nas coordenadas geográficas 6²4'04' latitude e $38^{\circ} 51^{\prime}$ '44' longitude, com limitações geográficas ao norte: Pereiro, Jaguaribe e Orós; ao Sul: Cedro, Lavras da Mangabeira, Umari; ao leste: Umarí, Estado da Paraíba e estado do Rio grande do Norte; e ao oeste: Orós, Iguatu e Cedro. Possui área absoluta de 1871,98km² e está localizada na Mesorregião Centro-Sul Cearense e na Macrorregião de Planejamento Cariri Centro-Sul (IBGE 2011).

O PIB da cidade está descrito em 78,98\% na área de serviços, $10,76 \%$ na parte agropecuária e 10,26\% na indústria (IPECE, 2009). Com a predominância da parte empregatícia na área de serviços, fator típico em pequenas cidades brasileiras, a cidade conta com a ajuda das pequenas empresas que detêm a maior participação na renda da cidade para o desenvolvimento urbano, sendo o ato empreendedor das empresas fato primordial para impulsionar a economia local.

\section{Metodologia da pesquisa}

Esta pesquisa se caracteriza como uma pesquisa quantitativa descritiva, do tipo survey, sendo um estudo de corte transversal realizado na cidade de Icó.

De acordo com Malhotra (2001), a pesquisa descritiva tem o objetivo de descrever alguma coisa ou população, ou seja, mostrar suas características ou funções de fato. São dois os métodos que podem ser realizados: método survey e método de observação. O método survey (ou comunicação) é a abordagem da pesquisa; já o por observação é a de observação em caráter pessoal, observação mecânica, análise de conteúdo e análise de sinais.

A pesquisa survey pode ser caracterizada como a coleta de dados ou informações sobre características, ações ou opiniões de determinado grupo de pessoas identificadas como os representantes de uma população-alvo, sendo estudada através de um ou mais instrumentos de pesquisa (FREITAS et al., 1999). 
Considerando que diversos são os conceitos de nomeação das empresas quanto ao porte, a utilizada para esta pesquisa foi o conceito de pequena empresa descrito pelo SEBRAE (2005): na indústria, de 20 a 99 pessoas; no comércio e serviços, de 10 a 49 pessoas e renda anual não superior a $\mathrm{R} \$ 1,2$ milhão.

Como amostra, foram utilizadas empresas cadastradas na Câmara de Dirigentes Lojistas (CDL) da cidade de Icó, a qual possui 164 empresas, de acordo com ficha fornecida pela própria associação. No entanto, foram excluídas 60 empresas, por não serem adequadas como pequenas empresas de acordo com o SEBRAE (2005). Outras 10 também foram descartadas, por estarem localizadas em outras cidades. Assim, a amostra foi composta por 94 empresas, das quais apenas 60 aceitaram participar da pesquisa (36,5\% da população).

O questionário aplicado possui divisão em três partes, das quais a primeira buscava identificar o perfil socioeconômico das empresas; a segunda continha 11 questões adaptadas de Conant et al. (1990), que objetivava captar o comportamento estratégico das empresas utilizado por Gimenez et al. (1999), Ribeiro et al. (2005) e outras séries de pesquisas isso pela sua eficiência e baixo índice de erro, conforme Gimenez (1999); e a terceira parte buscava captar a percepção de munificência dos empresários quanto ao ambiente em que estão localizadas - essa questão foi embasada nas três dimensões descritas por Castrogiovani (1991), sendo adaptada e utilizada por Ribeiro et al. (2005) e por Jogaratnam et al. (1999).

Foi utilizado o Termo de Consentimento Livre e Esclarecido (TCLE) para todos os proprietários que optaram por participar da pesquisa, mostrando os critérios éticos e as normas da pesquisa, além do teor cientifico que a pesquisa fomenta. Foi realizado ainda um estudo piloto em três empresas para testar a viabilidade do questionário e nenhuma observação foi encontrada. Para a análise estatística, foram utilizados os softwares Excel e GraphPad Prisma 5.0. A aplicação dos questionários se deu de duas formas, sendo entregue na própria empresa e também através do questionário on-line para as empresas que dispunham de endereço eletrônico. 
A classificação das empresas foi de acordo com o tipo estratégico: defensora, prospectora, analista ou reativa. Foi a mesma de Conant et al. (1990) e Ribeiro et al. (2011), a qual depende da quantidade de respostas dada a cada tipologia. O maior número de respostas representa o tipo estratégico da organização e, em situações de empate entre o número de alternativas, o critério estabelece que, se ocorrer entre o comportamento estratégico defensivo, prospector e/ ou analista, o resultado será registrado como analista, no entanto, se o empate abranger o comportamento reativo, a organização classificar-se-á como reativa.

Na terceira parte do questionário, em que os fatores de percepção do ambiente externo foram medidos (munificência), utilizou-se a mesma abordagem do estudo de Gardellin (2010), numa escala intervalar de 1 a 10, representando a percepção do respondente e sendo 1 a percepção de muito poucos recursos no ambiente (hostilidade) e 10 a percepção de muitos recursos disponíveis (munificente). Os resultados foram medidos de acordo com a média das respostas, sendo então considerado: 1) hostilidade (1 a 2,50); 2) baixa munificência (2,51 a 5,00); 3) alta munificência $(5,01$ a 7,50) e 4) máxima munificência $(7,51$ a 10,00).

\section{Análise e discussão dos resultados}

Os dados foram coletados em empresas de ramos diferentes e os segmentos identificados na amostra remetem a uma representatividade das empresas presentes no universo como um todo. De acordo com os integrantes da amostra, pode-se dizer que o mercado de produtos e serviços comanda a economia local, enquanto a parte industrial é incipiente (Tabela 1).

Tabela 1: Tipo de empresa

\begin{tabular}{lcc}
\hline Tipo de empresa & N & $\%$ \\
\hline Comercio de produtos & 46 & 77 \\
Comercio de serviços & 12 & 20 \\
Indústria em geral & 2 & 3 \\
\hline
\end{tabular}

Fonte: Dados da pesquisa. 
A maior parte $(77 \%)$ das empresas participantes é do setor de comercialização de produtos, compostos por lojas de roupas, calçados, móveis, farmácias, mercadinhos dentre outras empresas que atendem as necessidades básicas da população, necessidades comuns a qualquer cidade do interior do estado.

Outra característica considerável foi o fato de $54 \%$ dos participantes abordados serem do sexo feminino e se identificarem como socioproprietária ou gerente da empresa, podendo-se perceber a grande atuação da mulher no cenário empreendedor local.

Já em relação ao índice educacional dos participantes, percebeuse que $40 \%$ dos gestores estão cursando ou já concluíram o ensino superior, o que confirma a afirmação de Gimenez (2000) pelo nascimento de uma nova linha de gestão mais qualificado teoricamente. A maioria dessas empresas está há mais de 10 anos no mercado (Tabela 2).

Tabela 2: Idade da empresa

\begin{tabular}{lcc}
\hline Tempo no mercado & $\mathbf{n}$ & $\%$ \\
\hline Ate 5 anos & $\mathbf{1 7}$ & $\mathbf{2 8}$ \\
De 6 a 10 anos & 18 & 30 \\
Acima de 10 anos & $\mathbf{2 5}$ & $\mathbf{4 2}$ \\
\hline
\end{tabular}

Fonte: Dados da pesquisa.

O fato de a maioria das empresas locais possuir mais de 10 anos de atuação no mercado demonstra o padrão de maturidade dessas empresas. A maioria já está no mercado há gerações, e se tratando de empresas familiares o planejamento tende a ser cada vez menor e ineficiente, contribuindo para um comportamento característico de atuação no mercado.

Em um estudo feito com 36 indústrias paulistas, verificouse que $56 \%$ elaboram o planejamento estratégico (NASCIMENTO, 2002). Esses resultados alertam sobre a importância do planejamento estratégico como fator primordial para o crescimento no que diz respeito à competitividade empresarial. 
Tabela 3: Comportamento estratégico das empresas icoenses

\begin{tabular}{|l|c|c|}
\hline Comportamento estratégico & Frequência & Frequência relativa \\
\hline Prospector & 22 & 36 \\
\hline Analítico & 13 & 22 \\
\hline Defensor & 8 & 14 \\
\hline Reativo & 17 & 28 \\
\hline Total & 60 & $100 \%$ \\
\hline
\end{tabular}

Fonte: Dados da pesquisa.

Uma informação preocupante identificada pela pesquisa foi a representação de $28 \%$ das empresas como sendo reativas de acordo com o seu comportamento estratégico. As empresas com comportamento reativo, embora percebam as mudanças que ocorrem no mercado, não conseguem responder eficientemente pela inflexibilidade ou mesmo pela falta de recursos. Outro fator de destaque para esse comportamento é o fato de as empresas não possuírem uma estratégia definida.

Porém, em âmbito geral, descrevem-se as empresas icoenses como sendo, na maior parte, prospectoras (36\%). O segundo comportamento mais expressivo nas empresas é o reativo (28\%), seguido por analítico (22\%) e, por fim, o comportamento defensivo (14\%).

O comportamento reativo, segundo Miles e Snow (1978), é um perfil empresarial pouco competitivo, por isso, o menos apto a sobreviver em um ambiente turbulento. Isso porque o advento de pouco inovador, que não possui grande preocupação com os recursos humanos, e o improviso em situações problemáticas acabam atrapalhando o desempenho organizacional.

A predominância de empresas prospectoras remete a imaginar que sejam favoráveis a esse tipo de comportamento, conforme embasado por Miles e Snow (1978), os quais afirmam que em ambientes mais dinâmicos é comum que as empresas sejam em sua maioria prospectoras e em ambientes mais estáveis há a predominância de empresas com comportamento defensivo. 
Com relação aos tipos estratégicos e à percepção de munificência entre as empresas icoenses pode-se afirmar que não há diferença estatística quanto a se comportar de determinada maneira e perceber maior ou menor presença de recursos no ambiente (Figura 2).

Figura 2: Intercessão comportamento estratégico e munificência (ANOVA)

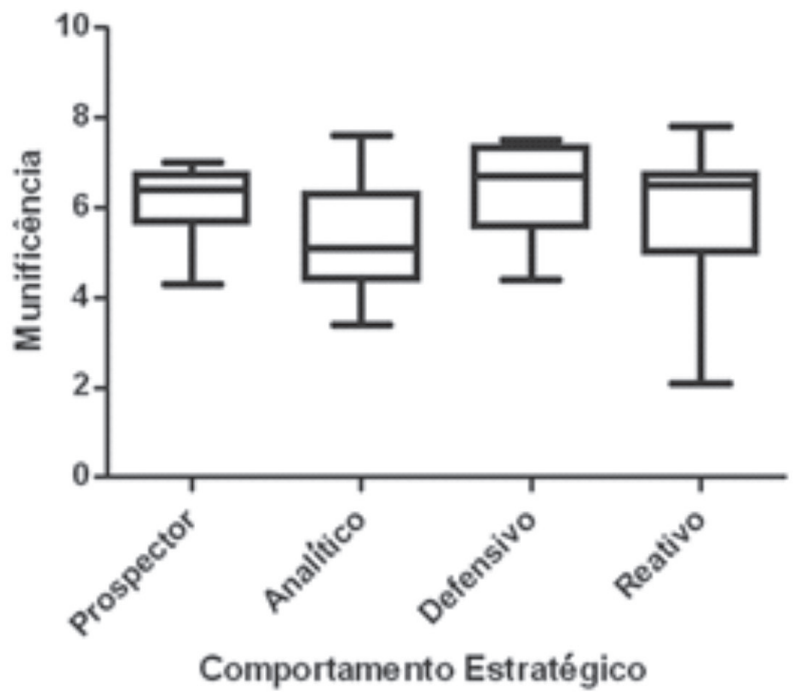

Fonte: Dados da pesquisa.

As empresas com comportamento reativo obtiveram uma maior variabilidade de percepções quanto à munificência do ambiente. Isso se explica pelo próprio perfil dessas empresas, que não possuem um planejamento adequado, levando-as ao improviso no momento de utilizar as ferramentas disponíveis no ambiente com vistas a maximizar sua participação no mercado.

A explicação mais provável para o fato de, ao levar em conta os quatro tipos de comportamento, não ter detectado diferença estatística quanto à percepção de munificência ao ambiente foi o pouco efeito observado, ou seja, a pouca diferença entre os comportamentos, necessitando de diferenças muito críticas para ser observado (Tabela 4). 
Tabela 4: Resultados da ANOVA

\begin{tabular}{lccccc}
\hline ANOVA Table & SS & Df & MS & F & P \\
\hline Treatment (between columns) & 7,698 & 3 & 2,566 & 2,022 & \\
Residual (within columns) & 71,08 & 56 & 1,269 & & 0,0677 \\
Total & 78,78 & 59 & & & \\
\hline
\end{tabular}

Fonte: Dados da pesquisa.

Conforme Miles e Snow (1978), é possível fazer a análise levando em consideração cada problema do ciclo adaptativo em separado. E assim foi analisado (Tabela 5).

No problema empreendedor, as empresas demonstraram características analíticas de comportamento representando $37 \%$ das empresas. Na dimensão empreendedora, abrangem-se três importantes características: domínio de produto-mercado, postura de sucesso e o monitoramento ambiental. Com a predominância do comportamento analista, pode-se dizer que organizações são relativamente cuidadosas em novas ideias e inovações no mercado, apresentam também um monitoramento de mercado mediano, porém, não muito agressivo e intenso, como demonstrado por uma parte prospectora (26\%), conforme a Tabela 5.

Tabela 5: Média geral dos problemas estratégicos de Miles e Snow

\begin{tabular}{lcccccc}
\hline \multirow{2}{*}{$\begin{array}{l}\text { Comportamento } \\
\text { estratégico }\end{array}$} & \multicolumn{2}{c}{$\begin{array}{c}\text { Problema } \\
\text { empreendedor }\end{array}$} & \multicolumn{2}{c}{$\begin{array}{c}\text { Problema de } \\
\text { engenharia }\end{array}$} & \multicolumn{2}{c}{$\begin{array}{c}\text { Problema } \\
\text { administrativo }\end{array}$} \\
& $\mathbf{n}$ & $\%$ & $\mathbf{n}$ & $\mathbf{\%}$ & $\mathbf{n}$ & $\%$ \\
\hline Prospector & 16 & 26 & 24 & 40 & 19 & 31 \\
Analítico & 22 & 37 & 12 & 20 & 15 & 25 \\
Reativo & 12 & 20 & 16 & 26 & 12 & 20 \\
Defensivo & 10 & 17 & 8 & 14 & 14 & 24 \\
\hline
\end{tabular}

Fonte: Dados da pesquisa.

Em síntese, o problema de engenharia trata principalmente dos critérios tecnológicos, visando o objetivo ao qual a tecnologia deve suprir e sua atualização. As empresas da cidade demonstrarão em maior parte 
comportamento prospector, marcado pela flexibilidade e inovação, com recursos humanos aptos ao manuseio tecnológico.

No problema administrativo, cujo foco é planejamento, estrutura e controle dos processos gerenciais, pode-se dizer que, das empresas estudadas, $31 \%$ apresentaram comportamentos e soluções prospectoras para esse problema, deixando parecer que estão constantemente em busca de oportunidades no mercado, suas estruturas são adequadas aos produtos e mercados, possuem controle em destaque para o desempenho no mercado e volume nas vendas.

Já no que diz respeito à munificência ambiental, o cenário icoense apresenta favorável presença de recursos nos indicadores ambientais pesquisados, conforme Gráfico 1:

Gráfico 1: Percepção da munificência por recursos ambientais

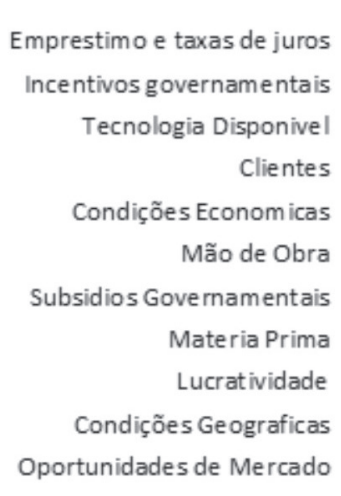

Fonte: Dados da pesquisa.

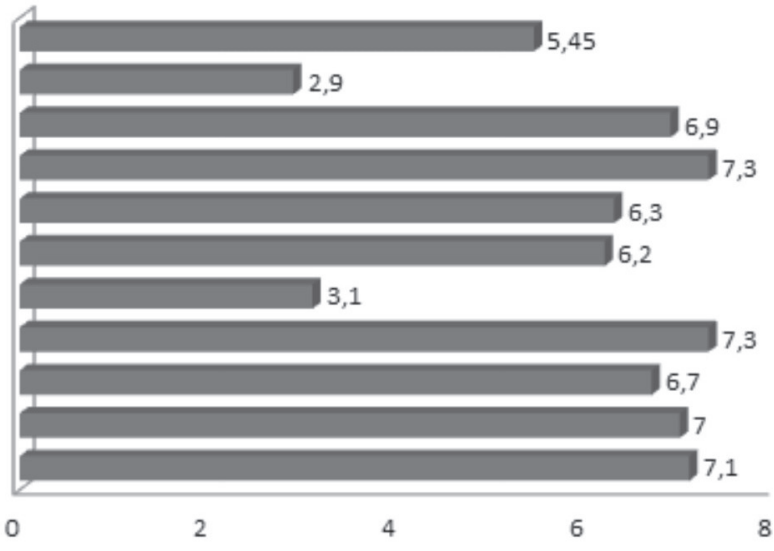

Os recursos de incentivos e subsídios governamentais são os únicos considerados como de baixa munificência $(2,5-5,0)$, ou seja, estão menos acessíveis às empresas. De fato, essa variável em todas as pesquisas realizadas com pequenas empresas com a utilização do questionário de Castrogiovani (1991) no Brasil apresentou baixa munificência. Dessa forma, percebe-se que não é um fato isolado da cidade, mas uma realidade nacional. 
O ambiente percebido pelos empresários das pequenas empresas na cidade de Icó é tido como alto munificente. Cabe dizer, portanto, que as pequenas empresas locais vivem em um ambiente favorável ao crescimento e que os casos de insucesso das empresas devem ser explicados por algo diferente da falta de recursos externos que proporcionem condições adequadas de sobrevivência para as empresas.

Esse ambiente farto de recursos, adicionado ao comportamento empreendedor da classe empresarial, tem impulsionado as empresas instaladas na cidade a se reestruturarem no seu modelo de gestão e também na parte estrutural física das empresas. Os turistas que chegam ao Vale do Salgado percebem um novo mercado, formado por empresas modernas que acompanham as tendências dos grandes centros econômicos do país.

Em uma visão geral e mais detalhada, pode-se ver a notificação dos empresários quanto à munificência do ambiente externo na cidade, conforme Gráfico 2:

Gráfico 2: Percepção geral de munificência

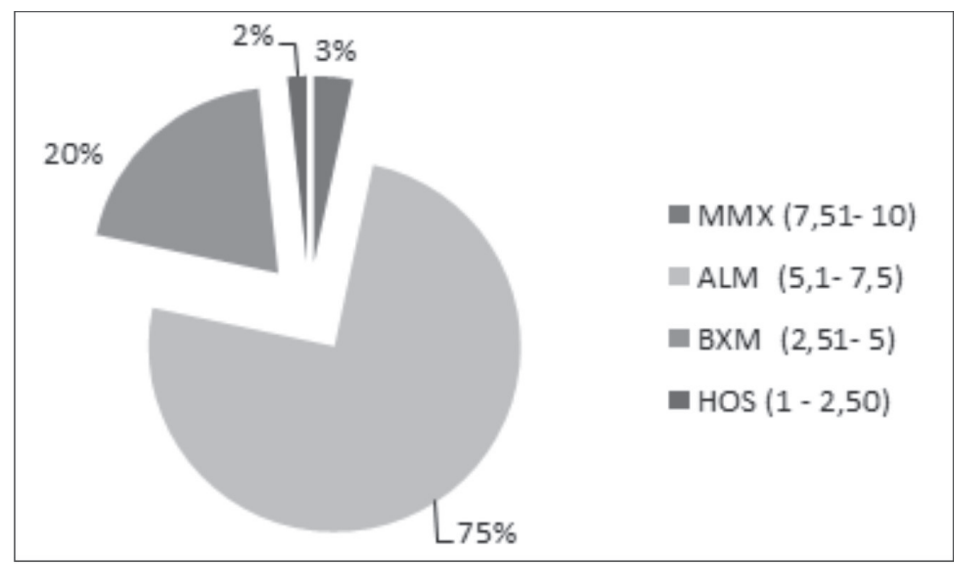

Fonte: Dados da pesquisa.

Pode-se afirmar que o cenário icoense, de acordo com os gestores, é considerado altamente munificente, ou seja, há a disponibilidade 
adequada de variáveis, como empréstimos, clientes, margem de lucro favorável e ambiente cercado de oportunidades a serem exploradas.

Escobar et al. (2012) concordam que ambientes com alta munificência de recursos são mais comuns em cidades em desenvolvimento e que essa condição influencia no aparecimento de empresas prospectoras. A munificência de recursos nessa região se deve principalmente ao desenvolvimento da cidade e de toda a macrorregião Centro-Sul do Ceará, onde as 14 cidades juntas formam um poderoso bloco de comercialização em si.

A formulação e decisão da estratégia de uma organização têm início na análise do meio ambiente e das aptidões da organização. Para as empresas que convivem nesse ambiente empresarial, é de suma importância a contínua manutenção e adaptação das estratégias e tarefas no turbulento ambiente para que continue competindo e seja eficiente em suas ações (NEUMAN, 2009).

Dos gestores que denominaram o ambiente como de baixa munificência, $40 \%$ eram de comportamento estratégico analítico - fator compreensível, já que empresas analíticas são altamente cuidadosas quanto às tomadas de decisões, fazendo cálculos minuciosos e não ariscando seus recursos, facilmente sendo dominada por assessores e controlada por matriz.

Quanto à baixa munificência identificada pelas empresas cadastradas na CDL de Icó, estão os indicadores de subsídios governamentais e incentivos governamentais, que trazem a discussão sobre a atenção dada aos empresários da região por parte do governo que não atende com as necessidades demandadas.

\section{Conclusão}

O objetivo deste estudo foi avaliar o comportamento estratégico de pequenas empresas icoenses através da taxonomia de Miles e Snow (1978), sendo analisada também a presença de recursos externos pela 
visão dos gestores, fazendo um cruzamento entre o comportamento e o ambiente externo disponível.

O referido estudo poderá auxiliar os gestores das futuras ou atuais empresas que atuam no mercado local, mostrando as tendências, de acordo com as decisões estratégicas e pensamentos cognitivos.

De acordo com a pesquisa, as empresas da cidade de Icó são, em sua maioria, prospectoras e reativas. Isso infere que são inovadoras, buscam continuamente mudanças, reagem rápido aos problemas do mercado e impulsionam suas concorrentes a mudar. De fato, é perceptível que a cidade de Icó deixa seus casarões centenários e todo o largo do Théberge para redesenhar seu novo mercado empresarial, tornando-o hoje um dos principais mercados do Centro-Sul cearense.

Em contrapartida, o comportamento reativo, sendo o segundo com maior incidência sobre as empresas da cidade, é de grande preocupação, já que elas apresentam um comportamento nada elegante, pois empresas reativas, além de possuírem pouca instrução sobre P\&D, não têm estratégia definida e quando identificado um problema de mercado não possuem instrução para repará-lo. Isso retrata bem as empresas familiares que passam entre gerações e não possuem capital intelectual para traçar novos caminhos, o que se reflete em velhas operações e métodos ineficazes, além de uma estrutura ultrapassada.

Já com relação à munificência de recursos, mostrou-se o ambiente de Icó como de alta munificência, independentemente do tipo de comportamento estratégico, havendo apenas a denominação de baixa munificência nos casos de subsídios governamentais e incentivos governamentais. Involuntariamente, lança-se a crítica contra o setor público, que tem dado pouca importância ao comércio local.

Ambiente com alta munificência quer dizer com muitos recursos, isso é realmente aparente na cidade, sendo a segunda mais populosa da região Centro-Sul. Perdendo apenas para Iguatu, Icó é localizada numa região privilegiada, com excelente acesso, berço de um grandioso patrimônio histórico e com abundância em água o ano todo. 
Empresas comprometidas com a inovação, somando-se a um ambiente favorável, ocasionam crescimento e sucesso organizacional. Desse modo, Icó é considerada uma cidade em crescimento, capaz de surpreender até os mais pessimistas. Em síntese, o fato de o ambiente pesquisado ser altamente munificente quebra o paradigma popular de que a cidade é "atrasada" e não dispõe de recursos capazes de induzir o crescimento empresarial.

Pode-se até questionar se realmente as empresas icoenses são prospectoras, uma vez que a cidade é reconhecida pela sua cultura e acervo arquitetônico secular. O cenário icoense não é tão diferente de outros cearenses e nordestinos, pois o padrão da clientela dessa cidade tem acompanhado tendências nacionais pela globalização, ficando assim mais exigentes. O fato lança como desafio diário às empresas locais evoluírem, mesmo que no ritmo particular delas, mas na intensidade e complexidade que o mercado exige.

Apesar de alguns dos resultados deste estudo não poderem ser considerados conclusivos, a pesquisa contribuiu com a evolução dos trabalhos sobre estratégia em pequenas empresas no Nordeste, demonstrando uma relação entre comportamento estratégico e munificência ambiental. Esse resultado sugere a importância de se investigar a relação entre ambiente e estratégia, e que as cidades do Nordeste não possuem diferenças bruscas em relação a outras empresas na região Sul, mesmo com índices e cenários econômicos diferentes.

Como limitação do trabalho, pode-se citar a não expansão do numero da amostra, pois houve complicações no recolhimento dos questionários, exigindo um tempo maior e dedicação extra em contatos com as empresas.

Também se pode apontar como limitação a dificuldade de se mensurar o tipo estratégico sem que seja a partir do exposto pelos gestores. Há pesquisadores críticos na mensuração do alinhamento estratégico que alertam para a necessidade e dificuldade de se mensurar a estratégia real utilizada pelos gestores no dia a dia da empresa, contudo, esta pesquisa fez uso apenas de mensuração do 
comportamento e estratégia esposada, ou seja, aquela expressa pelos gestores, mas não necessariamente utilizada.

Desse modo, a pesquisa deixa o espaço para continuação e sucessão de novos estudos que venham a contribuir e mesmo utilizar os conhecimentos acerca do ambiente e comportamento das empresas da cidade de Icó em prol do melhor conhecimento sobre a área.

\section{Referências}

ARCHER, F. B. et al. O modo de monitoramento do ambiente e o comportamento estratégico de uma unidade operativa do Senac da região oeste de Santa Catarina. In: ENCONTRO NACIONAL DAASSOCIAÇÃO NACIONAL DE PÓS-GRADUAÇÃO EM ADMINISTRAÇÃO, 35., 2011, Rio de Janeiro. Anais... Rio de Janeiro: Universidade do Vale do Itajai, 2011. p. 06-08.

BANDEIRA-DE-MELLO, R.; CUNHA, C. J. C. de A. Administrando o risco: uma teoria substantiva da adaptação estratégica de pequenas empresas a ambientes turbulentos e com forte influência governamental. Revista de Administração Contemporânea, Curitiba, v. 8, n. especial, 2004, p. 157-180.

BARRALES-MOLINA, V.; BENITEZ-AMADO, J.; PEREZ-AROSTEGUI, M.N. Managerial perceptions of the competitive environment and dynamic capabilities generation. Industrial Management \& Data Systems, Granada, v. 110, n.9, p. 1355-1384, , November, 2010.

BRASIL. Perfil dos municípios brasileiros: população e indicadores sociais. - Rio de Janeiro: IBGE, 2011. Disponível em: <http://www. ibge.gov.br/cidadesa t/xtras/temas .php?codmun=2 30540\&idtema=0>. Acesso em: 20 maio 2013.

BRESSAN, F.; SUGAHARA, C. R.; GEORGES, M. R. R. Escolhas estratégicas, modelos mentais do empreendedor e a tipologia de Miles e Snow: análise comparativa sob a ótica do modelo de Keirsey e Bates. In: XXXI ENCONTRO NACIONAL DE ENGENHARIA DE PRODUCAO, 
31, 2011, Belo Horizonte, Anais... Belo Horizonte: ABEPRO, 2011. p. 09-11.

CASTROGIOVANNI, G. J. Environmental Munificence: A theorical Assessment. Academy of Managment Review, Dallas, v.16, n. 3, p.542-565, August, 1991.

CHANDLER, A. D. Strategy and structure. Cambridge: MIT Press, 1962.

CHICHOSKI, I. O.; CERETTA, G. F.; ROCHA, A. C. Comportamento estratégico baseado na tipologia de Miles e Snow: Um estudo com empresas do setor industrial de Ampére - PR. Revista Eletrônica Qualitas. João Pessoa, v. 14. n. 1, p. 1-12, Jan./Jun, 2013.

COCHIA, C. B. R.; MACHADO-DA-SILVA, C. L. Ambiente, interpretação e estratégia em organizações paranaenses dos setores de vestuário e alimentos. Revista de Administração Contemporânea, Curitiba, v. 8, n. especial, p. 11-35, Dez. 2004.

CONANT, J. S.; MOKMA, M. P.; VARADARAJAN, P. R. Strategic types, distinctive marketing competencies and organisational performance: a multiple measures-based study. Strategic Management Journal, London, v.11, n. 5, p. 365-383, September, 1990.

ESCOBAR, M. A. R.; LIZOTE, S. A.; VERDINELLI, M. A. Relação entre orientação Empreendedora, capacidade de inovação e munificência Ambiental em agências de viagens. Revista Turismo Visão e Ação, Itajai, v. 14, n. 2, p. 269 -28, mai./ago., 2012.

ESCOBAR, M. A. R. Relação das capacidades dinâmicas e orientação empreendedora com o desempenho em agências de viagens moderada pelo ambiente organizacional. 2012. 190 f. Tese (Doutorado em Administração) - Universidade do Vale do Itajaí, Biguaçu, 2012.

FAGUNDES, F. M.; GIMENEZ, F. A. P. Ambiente, estratégia e desempenho em micro e pequenas empresas. REBRAE, Revista 
Brasileira de Estratégia, Curitiba, v. 2, n. 2, p. 133-146, maio/ago., 2009.

FREITAS, H.; OLIVEIRA, M.; SACCOL, A. Z.; MOSCAROLA, J. O método de pesquisa Survey. Revista de Administração, São Paulo, v. 35, n. 3, p. 105-112, jul./set., 2000.

FROES, E. B. Estratégia em micro e pequenas empresas: um estudo das empresas finalistas do premio Realce Empresarial. Salvador, 2008. 189 f. Dissertação (Mestrado em Administração)-Universidade Federal da Bahia, Salvador, 2008.

GARDELIN, J. P. O comportamento Estratégico e a percepção de incerteza e munificência de Micro e Pequenas Empresas. 2010. 137 f. Dissertação (Mestrado em Administração) - Universidade do Vale do Itajaí, Biguaçu, 2010.

GARDELIN, J. P; ROSSETTO, C. R.;VERDINELLI, M. A. A Percepção da Munificência Ambiental e a sua Relação com o Comportamento Estratégico em Pequenas Empresas na cidade de Tapejara (RS) In: VII CONVIBRA ADMINISTRAÇÃO. 7., 2010. São Paulo. Anais..., São Paulo, 2010. CD-ROM.

GIMENEZ, Fernando A. P. et al. Estratégia em pequenas empresas: uma aplicação do modelo de miles e snow. Rev. adm.contemp., Curitiba, v.3, n.2, Aug. Mai/Ago,1999.

GRANDE, I. S.; GEUS, L. M.; GEUS, A. C. L. Micro, pequenas e medias empresas: competitividade e inovação. In: ENCONTRO DE ENGENHARIA E TECNOLOGIA DOS CAMPOS GERAIS. 3., 2007, Ponta Grossa. Anais... Ponta Grossa: Centro de Ensino Superior dos Campos Gerais, 2007. CD-ROM

GULINI, P. L. Ambiente Organizacional, Comportamento Estratégico e Desempenho Empresarial: um estudo no setor de provedores de internet de Santa Catarina. 2005. 160 f. Dissertação (Mestrado Acadêmico em Administração) - Universidade do Vale do Itajaí, BiguaçuSC, 2005. 
GURKOV, Igor. Dominant strategic archetype of the Russian industrialfirm, Journal for East European Management Studies, Hampp, Mering, v. 12, n. 1, p. 35-52, Jan-Mar, 2007.

HAIR JUNIOR, J. F. et al. Fundamentos de métodos de pesquisa em administração. Porto Alegre: Bookman, 2005.

HALL, R. Organizações: estruturas e processos. 3. ed. Rio de Janeiro: Prince Hall do Brasil, 1984.

HAMBRICK, D. C. High profit strategies in mature capital goods industries: a contingency approach. Academy of Management Journal, Dallas, v. 26, n. 4, p. 687-707, Aug.,1983.

JOGARATNAM, G. et al. Strategic Posture, Environmental Munificence, and Performance: Empirical Study of Independent Restaurants. Journal of Hospitality \& Tourism Research, Pennsylvania, v. 23, n. 2, p. 118138, May, 1999.

LAKATOS, E. M.; MARCONI, M. A. Fundamentos de Metodologia Científica. São Paulo: Atlas, 2003.

LAWRENCE, P. R.; LORSCH, J. W. As Empresas e o Ambiente: diferenciação e integração administrativas. Petrópolis: Vozes, 1973.

MALHOTRA, N. K. Pesquisa de marketing: uma orientação aplicada. 3. ed. Porto Alegre: Bookman, 2001.

MARCIAL, E. C.; GRUMBACH, R. J. S. Cenários Prospectivos: como construir um futuro melhor. 5. ed. Rio de Janeiro: Editora FGV, 2008.

MAXIMIANO, A. C. A. Introdução à Administração. 7. ed. versão ampliada. São Paulo: Atlas, 2007.

MILES, R. E.; SNOW, C. C. Organizational strategy, structure and process. New York: McGraw-Hill, 1978.

MINTZBERG, H. Generic strategies: toward a comprehensive framework. Advances in Strategic Management, Stamford, v. 5, n. 1, p. 01-67, Jan., 1988. 
- Criando organizações eficazes: estruturas em cinco configurações. 2. ed. São Paulo: Atlas, 2008.

MINTZBERG, H.; AHLSTRAND, B. W.; LAMPEL, J. Safári de estratégia: um roteiro pela selva do planejamento estratégico. Porto Alegre: Bookman, 2000.

MORGAN, G. Imagens da organização. São Paulo: Atlas, 1996.

MOTTA, P. R. Gestão contemporânea: a ciência e a arte de ser dirigente. 13. ed. Rio de Janeiro: Record, 2002.

NEUMANN, S. E. Planejamento Estratégico: uma investigação da prática nas empresas do setor mecânico da serra gaúcha. 2009. 170 f. Dissertação (Mestrado em Administração)-Universidade de Caxias do Sul, Rio Grande do Sul, 2009.

OLIVEIRA, D. P. R de. Estratégias empresariais \& vantagem competitiva: como estabelecer, implementar e avaliar. 6. ed. São Paulo: Atlas, 2009.

Estratégia empresarial \& vantagem competitiva: como estabelecer implementar e avaliar. 3. ed. São Paulo: Atlas, 2001.

RIBEIRO, R.; ROSSETO, C. R.; VERDINELLI, M. A. Comportamento estratégico da empresa e a visão baseada em recursos: um estudo no setor varejista de material de construção. Gest. Prod., São Carlos, v. 18, n. 1, p. 175-192, Jan/Mar., 2011.

SERVIÇO BRASILEIRO DE APOIO ÀS MICRO E PEQUENAS EMPRESAS (SEBRAE). Estudos da pequena empresa. Disponível em: <www.sebrae.com.br> Acesso em: 13 fev. 2013.

TEIXEIRA, O. R. P. A relação entre ambiente e comportamento organizacional: um estudo no setor hoteleiro de Florianópolis - SC. 2007. 160 f. Dissertação (Mestrado Acadêmico em Administração) Universidade do Vale do Itajaí, Biguaçu-SC, 2007.

TONDOLO, V. A. G.; TONDOLO, R. R. P. Heterogeneidade dos recursos e mudanças na gestão organizacional: um estudo de caso no 
agronegócio cooperativo gaúcho. In: ENCONTRO ANUAL DA ANPAD, 30, 2006, Salvador, Anais... Salvador/Bahia: ANPAD, 2006. p.10-13

VIANA, C. M. P. et al. IPECE: Perfil Básico Municipal 2012. . Disponível em:http://www.ipece.ce.gov.br/publicacoes/perfil_basico/pbm-2012/lco. pdf acesso em: 10 Abr. 2013.

WIKLUND, J.; SHEPHERD, D. Entrepreneurial orientation and small business performance: a configurationally approach. Journal of Business Venturing, Toronto, v. 20, n. 1, p. 71-91, May, 2005.

Artigo recebido em: 11/07/2013

Aprovado em: 14/04/2014 